\title{
Serum spexin, adiponectin and leptin levels in polycystic ovarian syndrome in association with FTO gene polymorphism
}

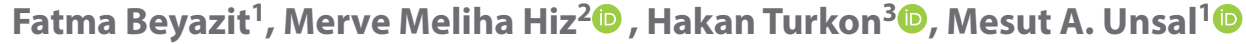 \\ ${ }^{1}$ Department of Obstetrics and Gynecology, Faculty of Medicine, Canakkale Onsekiz Mart University, Canakkale, Turkey \\ ${ }^{2}$ Department of Medical Biology, Faculty of Medicine, Canakkale Onsekiz Mart University, Çanakkale, Turkey \\ ${ }^{3}$ Department of Biochemistry, Meddem Hospital, Isparta, Turkey
}

\begin{abstract}
Objectives: Polycystic ovary syndrome (PCOS) is a complex reproductive endocrinopathy among reproductive-aged women and related with body mass and insulin resistance. Adipocytokines produced by adipose tissue seems to take part in the hormonal and metabolic alterations that arise in PCOS. Fat mass and obesity associated (FTO) gene is linked with body mass index (BMI) and diabetes.

Aims - To investigate the association between fat mass related adipocytokines and single nucleotide polymorphisms (SNPs) (rs9939609 T/A) in the FTO gene in women with PCOS.

Study design - Cross-sectional study

Material and methods: FTO+rs9939609 gene polymorphism and serum spexin, adiponectin and leptin levels were determined in 91 PCOS women and 86 healthy controls. Study participants were subdivided according to BMI and comparisons were made within each group.

Results: Serum spexin levels were not differed between study groups. Serum levels of adiponectin were found to be decreased in PCOS women with BMI lower than $25 \mathrm{~kg} / \mathrm{m}^{2}$ (10.1 $\left.\pm 5.6 \mathrm{vs} 14.1 \pm 9.1, \mathrm{p}=0.015\right)$. Serum leptin levels were elevated in obese PCOS women compared to healthy control group $(2197.9 \pm 596.3 \mathrm{pg} / \mathrm{mL}$ vs $1535.9 \pm 812.1 \mathrm{pg} / \mathrm{mL}, \mathrm{p}=0.001)$. The prevalence of A risk allele of SNP rs9939609 was more frequent in PCOS patients than in the control group. PCOS risk was found to increase 3 times more in AA genotype when compared with TT genotype ( $O R=3.0495 \% \mathrm{Cl}: 1.243-7.309 ; p=0.013)$. Conclusions: Serum adiponectin and leptin levels may serve as independent markers for PCOS diagnosis. Moreover, the FTO+rs9939609 gene polymorphism increase susceptibility to PCOS development independent from serum adipocytokine levels. Key words: PCOS; FTO gene polymorphism; spexin; adiponectin; leptin
\end{abstract}

Ginekologia Polska 2021; 92, 10: 682-688

\section{INTRODUCTION}

Polycystic ovarian syndrome (PCOS) is a common and serious cause of infertility which affects nearly five to ten percent of women of childbearing age across the World [1]. Although the clinical reflection of the disease can be variable, diagnostic characteristics commonly involve clinical complaints including menstrual irregularities that range from amenorrhea to menorrhagia, increased androgen secretion and/or polycystic ovaries [2]. In this context, the phenotypic expression varies in PCOS patients depending on whether the patient is lean, obese or having insulin resistance (IR) and increased adipokine expression regardless of the patient's body mass index (BMI) $[3,4]$.
There has been growing evidence that shows genetic aberrations also contribute to disease development by inducing immune and autoimmune responses $[5,6]$. Recently, more than one hundred candidate genes have been identified regarding the possible relationships between PCOS and single nucleotide polymorphism (SNP), for instance body mass and genetic variants of obesity associated (FTO) gene [7, 8]. The human FTO is a very large gene that is positioned on chromosome 16q12.2 with an extensive expression range in many human tissues [9]. Recent studies demonstrated that the FTO gene expression is strongly related with obesity by its impact on feeding behavior and energy expenditure [10, 11]. However, data

Corresponding author:

Fatma Beyazit

Department of Obstetrics and Gynecology, Canakkale Onsekiz Mart University, Canakkale, Turkey

e-mail: fatmabeyazit@yahoo.com

Received:13.06.2020 Accepted: 29.10.2020 Early publication date: 22.04.2021

This article is available in open access under Creative Common Attribution-Non-Commercial-No Derivatives 4.0 International (CC BY-NC-ND 4.0) license, allowing to download articles and share them with others as long as they credit the authors and the publisher, but without permission to change them in any way or use them commercially. 
regarding these associations and the pathophysiologic mechanisms underlying them needs further clarification.

Central obesity is the cornerstone of a variety of metabolic disorders, such as IR and coronary atherosclerosis and is an important element of metabolic syndrome. It has been suggested that dysregulation of adipocytokines is partly responsible for this obesity associated metabolic disorders [11]. Being a disease related with IR and central obesity, the role of adipose tissue adipocytokines has been implicated to play important roles in the pathogenesis of PCOS in the recent years.

Adipocytokines are proteins that have hormone like functions and secreted by the adipocytes in the adipose tissue [12]. The most significant physiological functions of adipose tissue are the regulation of physiological processes such as immune responses, reproduction, and energy hemostasis [4]. Adipocytokines that are expressed by the adipocytes consists of adiponectin, leptin, spexin, apelin, omentin, resistin, progranulin and chemerin. Adiponectin and leptin are two important adipocytokines and both have an effect on obesity, cardiovascular disease, type 2 diabetes mellitus and IR [13]. Adiponectin is an anti-inflammatory cytokine that regulates glucose and fatty acid metabolism, thus inversely related with the adipocyte mass and visceral adiposity. Leptin is a peptide hormone with neuroendocrine function that regulates in the energy homeostasis with having a key function in the peripheral regulation of food intake and energy expenditure and thereby IR $[14,15]$. Spexin is a neuropeptide identified by a hidden Markov model based on a computational method in order to detect novel biologically active peptides [16, 17]. Although, there is growing evidence on the existence of spexin gene expression in the adrenal cortex, kidney, liver, visceral fat and pancreas, very little is known about the association between ovaries and spexin expression.

As far as we know, no study in the literature has investigated the circulating spexin levels in PCOS women. Furthermore, the potential relationships of spexin and two other adipocytokines with body mass and associated metabolic disorders have not been well-examined. This study is, therefore, aimed to investigate the relationships between spexin, adiponectin, leptin and obesity associated metabolic disorders and FTO rs9939609 gene polymorphism in PCOS women.

\section{MATERIAL AND METHODS}

Study design and subjects

This cross-sectional study was conducted from August 2017 to September 2018 at the Canakkale University Hospital in Canakkale, Turkey. All participants attending to the Department of Obstetrics and Gynecology of COMU hospital with a diagnosis of PCOS were invited to participate in the study. The exclusion criteria included previous systemic, metabolic or endocrine disorders. Moreover, patients with thyroid disorders and arterial hypertension [systolic blood pressure (SBP) $\geq 140 \mathrm{mmHg}$ and/or diastolic blood pressure (DBP) $\geq 90 \mathrm{mmHg}$ ] prior to use of oral contraceptive agents; severe lipid profile abnormalities with/or without antihyperlipidemic drugs; or prescription of gonadotropinreleasing hormone agonists or antagonists, glucocorticoids, or antidiabetic drugs within the previous three months were also considered as exclusion criteria for the present study.

All study participants gave written informed consent, and the study was approved by the Canakkale University Human Research Ethics Committee (approval number: 2017-15). PCOS diagnosis was done based on the revised criteria of Rotterdam 2003. According to this consensus report, the diagnosis of PCOS can be considered after suitable clinical, laboratory and ultrasound criteria are fulfilled. The presence of at least two of the following three features are thought to be suitable for the exact diagnosis: oligomenorrhea or amenorrhea longer than 6 months, clinical and/or biochemical indicators of high levels of androgens, and finally, polycystic ovaries ( $\geq 12$ follicles) and/or increased ovarian volume $\left(>10 \mathrm{~cm}^{3}\right)$ which is identified by ultrasonographic examination.

Healthy controls were recruited from the Gynecology and Obstetrics clinic of Canakkale University Hospital. The control group consisted of 86 healthy, age-matched, normally ovulating women without any systemic or hormonal disorders. None of the controls were hirsute, all had regular menstrual cycle, and all had normal ovaries on ultrasonographic examination. Moreover, the volunteers in the control group had no clinical evidence of acne, hirsutism, male pattern alopecia, or any other endocrine disorder.

For each patient, height and weight were recorded in indoor clothing with no shoes. BMI was calculated as weight in kilograms divided by height squared $\left(\mathrm{m}^{2}\right)$.

\section{Biochemical analyses}

Between days 3-5 of a spontaneous menstrual cycle, a 6-mL fasting blood sample for hormonal and biochemical analysis and a 4-mL fasting blood sample for genotyping examination were drawn from the antecubital vein of each subject. The samples for biochemical analysis were subjected to centrifugation at a speed of 4,000 rounds per minute for $10 \mathrm{~min}$ at $4^{\circ} \mathrm{C}$ to obtain serum and stored for analysis at $-80^{\circ} \mathrm{C}$. Routine biochemical analysis and hormone profiles including fasting glucose, fasting insulin, prolactin, estradiol, luteinizing hormone (LH), follicle stimulating hormone (FSH), thyroid stimulating hormone (TSH), and total testosterone were measured for all participants. Biochemical tests were analyzed spectrophotometrically, using the Roche Diagnostic kits on the Cobas c501 auto-analyzer 
(Roche Diagnostics, Indianapolis, USA). Hormone tests were measured with the original Roche Diagnostic kits on the Cobas e601 using the electrochemiluminescence immunoassay method (Roche Diagnostics, Indianapolis, USA). IR was assessed by the Homeostasis Model of Assessment — Insulin Resistance (HOMA-IR) index [18].

\section{Spexin, adiponectin and leptin measurement}

Serum Spexin (EH4349, Fine Test, Wuhan, China), adiponectin (EH2593, Fine Test, Wuhan, China) and leptin (EH0216, Fine Test, Wuhan, China) concentrations were measured with an ELISA kit. Leptin and Spexin results were expressed as nanograms in per liter (pg/L) of serum. Adiponectin results were expressed as picograms in per liter ( $\mathrm{ng} / \mathrm{L}$ ) of serum. The intra-assay and inter-assay coefficients of variations were $<8 \%$ and $<10 \%$ for all parameters, respectively.

\section{Genotyping}

PCOS patients and healthy controls were genotyped at the Department of Medical Biology of Canakkale Onsekiz Mart University. The venous blood samples of both patients and control groups were collected in vacuum collection tubes containing EDTA. The Genomic DNA extracted from peripheral blood sample of all study participants and the assessment was done according to manufacturers' recommendations (Thermo Fisher Scientific, USA). DNA purity and concentration were calculated at $260 / 280 \mathrm{~nm}$ by UV spectrometer.

Single nucleotide polymorphism (SNP) rs9939609 (A/T) of FTO was genotyped directly by melting curve analyses. Briefly, real time polymerase chain reaction (PCR) was performed for each sample in a total volume of $10 \mu \mathrm{L}$ PCR reaction mixture that consisted of $50 \mathrm{ng}$ of genomic DNA, $5 \mu \mathrm{L}$ of $\mathrm{SYBR}^{\oplus}$ Green Realtime PCR Master Mix (Analytic-Jena, Germany), and $0.4 \mu \mathrm{L}$ of each primer (10 pmol/ $\mu \mathrm{L}$ ) filled with PCR-grade water. The PCR cycling protocol included initial activation at $95^{\circ} \mathrm{C}$ for 3 minutes, 40 cycles of denaturation at $95^{\circ} \mathrm{C}$ for 5 seconds, annealing at $60^{\circ} \mathrm{C}$ for 20 seconds, and extension at $72^{\circ} \mathrm{C}$ for 15 seconds. Melting curve analyses following PCR were performed to determine mutant, heterozygous, and wild-type genotypes.

\section{Statistical analyses}

Statistical Package for Social Sciences (SPSS) for Windows 19.0 (SPSS for Windows, SPSS, Chicago) was used for data analysis. Biochemical and hormonal parameter data are presented as mean \pm SD for normally distributed variables. The normality of numeric variables was checked by Kolmogorov-Smirnov test. Independent sample t test was used to compare the numeric variables that were normally distributed and Mann-Whitney $U$ test was used to compare the variables that non-normally distributed. Spearman's correlation coefficient analyses were performed between spexin, adiponectin and leptin with other biochemical and hormonal parameters, and $p$-value $<0.05$ was considered statistically significant. Gene-counting method was used to calculate allele and genotype frequencies. Genotype associations and relative risk assessments were done via odds ratio (OR) by using the Armitage trend test.

\section{RESULTS}

The demographic and biochemical characteristics of the study participants are summarized in Table 1. Although, mean age of PCOS patients and controls were similar $(26.5 \pm 6.2$ vs $28.8 \pm 7.2, p=0.050)$, PCOS women had a greater BMI $(26.0 \pm 5.3$ vs $24.1 \pm 4.4, p=0.008)$ than the healthy women. A statistically significant increase was observed in body weight, insulin levels and HOMA-IR status in PCOS patients compared to controls. Moreover, PCOS patients had a significant increase in $\mathrm{LH}$, total testosterone, and TSH levels (Tab. 1).

Serum spexin levels were similar in PCOS women. Although serum levels of adiponectin were decreased in women with PCOS either in obese $(10.2 \pm 6.7 \mathrm{ng} / \mathrm{mL}$ vs $13.5 \pm 8.2 \mathrm{ng} / \mathrm{mL}, \mathrm{p}=0.303$ ) or normal weight PCOS women $(10.1 \pm 5.6 \mathrm{ng} / \mathrm{mL}$ vs $14.1 \pm 9.1 \mathrm{ng} / \mathrm{mL}, \mathrm{p}=0.015)$, a statistical significance was observed only in normal weight PCOS subjects. Serum leptin levels were found to be increased in obese PCOS patients compared to controls $(2197.9 .3 \pm 596.3 \mathrm{pg} / \mathrm{mL}$ vs $1535.9 \pm 812.1 \mathrm{pg} / \mathrm{mL}, \mathrm{p}=0.001)$ (Tab. 1).

We explored potential correlations among serum spexin, adiponectin and leptin levels with other demographic, hormonal and clinical characteristics in PCOS patients. No significant correlation was observed between these parameters in PCOS patients except for spexin and adiponectin in BMI $<25 \mathrm{~kg} / \mathrm{m}^{2}$ PCOS group ( $r=0.356$, $\mathrm{p}=0.021$ ) (Tab. 2).

The correlation of FTO+ rs9939609 polymorphism with PCOS was examined by comparing PCOS patients with healthy volunteers. The distribution of the genotypes in the PCOS group were as follows: out of 91 cases, 29 were determined to have the wild (TT) genotype, 41 the heterozygous genotype (AT), and 21 the mutant genotype (AA). The wild allele frequency ( $T$ allele) for FTO+rs9939609 polymorphism was calculated as $0.53 \pm 0.039$ among PCOS patients, and the PCOS population was found to deviate from the Hardy-Weinberg equilibrium (HWE) ( $x^{2}: 0.047 ; p$-value: 0.224). The wild allele frequency (T allele) for FTO+ rs9939609 polymorphism was calculated as $0.66 \pm 0.037$, and none of the variants were found to deviate from the HWE in the control group $\left(x^{2}: 0.046\right.$; p-value: 0.829) (Tab. 3). 


\begin{tabular}{|c|c|c|c|c|c|c|c|c|c|}
\hline & \multicolumn{3}{|c|}{ All participants } & \multicolumn{3}{|c|}{ Normal weight subjects $\left(\mathrm{BMI}<25 \mathrm{~kg} / \mathrm{m}^{2}\right)$} & \multicolumn{3}{|c|}{ Overweight subjects (BMI $\geq 25 \mathrm{~kg} / \mathrm{m}^{2}$ ) } \\
\hline & $\begin{array}{c}P C O S \\
(n=91)\end{array}$ & $\begin{array}{l}\text { Controls } \\
(n=86)\end{array}$ & $\mathbf{p}$ & $\begin{array}{l}P C O S \\
(n=42)\end{array}$ & $\begin{array}{l}\text { Controls } \\
(n=56)\end{array}$ & $\mathbf{p}$ & $\begin{array}{c}\text { PCOS } \\
(n=49)\end{array}$ & $\begin{array}{l}\text { Controls } \\
(n=30)\end{array}$ & $\mathbf{p}$ \\
\hline $\begin{array}{l}\text { Age } \\
\text { [years] }\end{array}$ & $26.5 \pm 6.2$ & $28.8 \pm 7.2$ & 0.050 & $25.7 \pm 5.5$ & $27.1 \pm 6.3$ & 0.424 & $27.1 \pm 6.7$ & $31.8 \pm 7.7$ & 0.007 \\
\hline $\begin{array}{l}\text { Weight } \\
{[\mathrm{kg}]}\end{array}$ & $70.3 \pm 14.6$ & $64.7 \pm 11.4$ & 0.005 & $58.9 \pm 7.2$ & $58.6 \pm 6.5$ & 0.859 & $80.1 \pm 11.9$ & $75.9 \pm 10.1$ & 0.116 \\
\hline $\begin{array}{l}\mathrm{BMI} \\
{\left[\mathrm{kg} / \mathrm{m}^{2}\right]}\end{array}$ & $26.0 \pm 5.3$ & $24.1 \pm 4.4$ & 0.008 & $21.7 \pm 2.4$ & $21.5 \pm 2.1$ & 0.528 & $29.7 \pm 4.0$ & $28.9 \pm 3.4$ & 0.446 \\
\hline $\begin{array}{l}\text { Glucose } \\
{[\mathrm{mg} / \mathrm{dL}]}\end{array}$ & $93.8 \pm 13.8$ & $93.5 \pm 17.4$ & 0.792 & $92.6 \pm 12.6$ & $90.9 \pm 13.1$ & 0.778 & $94.8 \pm 14.9$ & $98.4 \pm 22.8$ & 0.812 \\
\hline $\begin{array}{l}\text { Insulin } \\
{[\mu \mathrm{IU} / \mathrm{mL}]}\end{array}$ & $12.8 \pm 9.0$ & $8.2 \pm 5.5$ & 0.0001 & $9.9 \pm 7.1$ & $7.8 \pm 5.4$ & 0.057 & $15.2 \pm 9.9$ & $9.1 \pm 5.7$ & 0.001 \\
\hline $\begin{array}{l}\text { HOMA-IR } \\
{[\%]}\end{array}$ & $2.9 \pm 2.1$ & $1.9 \pm 1.4$ & 0.0001 & $2.3 \pm 1.8$ & $1.8 \pm 1.3$ & 0.051 & $3.4 \pm 2.2$ & $2.3 \pm 1.5$ & 0.008 \\
\hline $\begin{array}{l}\text { TSH } \\
{[\mu \mathrm{l} / \mathrm{mL}]}\end{array}$ & $2.4 \pm 1.1$ & $2.2 \pm 1.2$ & 0.043 & $2.4 \pm 1.1$ & $2.2 \pm 1.3$ & 0.101 & $2.5 \pm 1.1$ & $2.3 \pm 0.9$ & 0.379 \\
\hline $\begin{array}{l}\mathrm{FSH} \\
{[\mathrm{mlU} / \mathrm{mL}]}\end{array}$ & $5.9 \pm 1.9$ & $5.3 \pm 2.2$ & 0.056 & $6.1 \pm 1.9$ & $5.1 \pm 2.0$ & 0.009 & $5.7 \pm 1.9$ & $5.8 \pm 2.4$ & 0.854 \\
\hline $\begin{array}{l}\mathrm{LH} \\
{[\mathrm{mlU} / \mathrm{mL}]}\end{array}$ & $7.8 \pm 2.9$ & $6.4 \pm 3.9$ & 0.001 & $7.9 \pm 2.7$ & $6.1 \pm 3.8$ & 0.003 & $7.8 \pm 3.1$ & $6.9 \pm 4.4$ & 0.189 \\
\hline $\begin{array}{l}T T \\
{[\mathrm{pg} / \mathrm{mL}]}\end{array}$ & $0.4 \pm 0.2$ & $0.3 \pm 0.1$ & 0.0001 & $0.3 \pm 0.2$ & $0.3 \pm 0.1$ & 0.082 & $0.4 \pm 0.2$ & $0.3 \pm 0.2$ & 0.002 \\
\hline $\begin{array}{l}\text { Spexin } \\
{[\mathrm{ng} / \mathrm{mL}]}\end{array}$ & $10.5 \pm 9.2$ & $12.6 \pm 9.8$ & 0.085 & $8.9 \pm 6.4$ & $12.4 \pm 10.5$ & 0.452 & $11.9 \pm 10.9$ & $12.9 \pm 8.3$ & 0.303 \\
\hline $\begin{array}{l}\text { Adiponectin } \\
{[\mathrm{ng} / \mathrm{mL}]}\end{array}$ & $10.2 \pm 6.2$ & $13.9 \pm 8.8$ & 0.002 & $10.1 \pm 5.6$ & $14.1 \pm 9.1$ & $0.015^{*}$ & $10.2 \pm 6.7$ & $13.5 \pm 8.2$ & 0.056 \\
\hline $\begin{array}{l}\text { Leptin } \\
{[\mathrm{pg} / \mathrm{mL}]}\end{array}$ & $1874.2 \pm 902.3$ & $1670.8 \pm 786.1$ & 0.112 & $1646.5 \pm 602.9$ & $1743.0 \pm 769.5$ & 0.112 & $2197.9 .3 \pm 596.3$ & $1535.9 \pm 812.1$ & 0.001 \\
\hline
\end{tabular}

BMI — body-mass index; HOMA-IR - homeostatic model assessment of insulin resistance; TSH — thyroid stimulating hormone; FSH — follicle-stimulating hormone; $\mathrm{LH}$ - luteinizing hormone; TT — total testosterone

Table 2. Correlation between serum spexin, adiponektin and leptin levels with biochemical and hormonal parameters

\begin{tabular}{|c|c|c|c|c|c|c|c|c|c|c|c|c|}
\hline & \multicolumn{6}{|c|}{ PCOS patients (BMI $\left.<25 \mathrm{~kg} / \mathrm{m}^{2}\right)$} & \multicolumn{6}{|c|}{ Controls (BMI $\geq 25 \mathrm{~kg} / \mathrm{m}^{2}$ ) } \\
\hline & \multicolumn{2}{|c|}{ Spexin } & \multicolumn{2}{|c|}{ Adiponectin } & \multicolumn{2}{|c|}{ Leptin } & \multicolumn{2}{|c|}{ Spexin } & \multicolumn{2}{|c|}{ Adiponectin } & \multicolumn{2}{|c|}{ Leptin } \\
\hline & $\mathbf{r}$ & p & $\mathbf{r}$ & p & $\mathbf{r}$ & p & $\mathbf{r}$ & p & $\mathbf{r}$ & p & $\mathbf{r}$ & p \\
\hline BMI $\left[\mathrm{kg} / \mathrm{m}^{2}\right]$ & -0.110 & 0.489 & -0.003 & 0.987 & 0.172 & 0.277 & 0.045 & 0.759 & 0.189 & 0.192 & 0.396 & 0.005 \\
\hline HOMA-IR [\%] & 0.053 & 0.740 & -0.097 & 0.541 & 0.028 & 0.861 & 0.095 & 0.515 & 0.031 & 0.835 & 0.161 & 0.269 \\
\hline $\mathrm{TSH}[\mu \mathrm{IU} / \mathrm{mL}]$ & -0.052 & 0.743 & 0.062 & 0.696 & -0.097 & 0.543 & -0.003 & 0.986 & -0.055 & 0.709 & -0.022 & 0.881 \\
\hline $\mathrm{FSH}[\mathrm{mlU} / \mathrm{mL}]$ & 0.051 & 0.750 & -0.110 & 0.486 & 0.185 & 0.241 & 0.139 & 0.342 & 0.069 & 0.639 & -0.080 & 0.586 \\
\hline $\mathrm{LH}[\mathrm{mlU} / \mathrm{mL}]$ & -0.009 & 0.953 & -0.218 & 0.166 & 0.087 & 0.585 & -0.009 & 0.953 & 0.022 & 0.883 & -0.023 & 0.878 \\
\hline $\mathrm{TT}[\mathrm{pg} / \mathrm{mL}]$ & 0.038 & 0.812 & -0.105 & 0.514 & -0.072 & 0.655 & -0.105 & 0.489 & -0.340 & 0.051 & 0.083 & 0.584 \\
\hline Estradiol & 0.023 & 0.886 & 0.174 & 0.271 & 0.098 & 0.536 & 0.119 & 0.416 & 0.148 & 0.310 & -0.241 & 0.096 \\
\hline Spexin [ng/mL] & - & - & 0.356 & 0.021 & 0.529 & 0.526 & - & - & 0.143 & 0.326 & 0.210 & 0.148 \\
\hline Adiponectin [ng/mL] & - & - & - & - & 0.194 & 0.217 & - & - & - & - & -0.067 & 0.648 \\
\hline Leptin [pg/mL] & & & & & & & & & & & & \\
\hline
\end{tabular}

$\mathrm{BMI}$ - body mass index; HOMA-IR — homeostasis model assessment of insulin resistance; TSH — thyroid stimulating hormone;FSH — follicle-stimulating hormone; $\mathrm{LH}$ - luteinizing hormone; TT — total testosterone 
Table 3. Distributions of genotype and carriage rate of FTO promoter region polymorphisms in patients with PCOS and healthy controls

\begin{tabular}{|c|c|c|c|c|c|c|c|}
\hline \multirow{2}{*}{ SNP } & \multicolumn{2}{|c|}{$\begin{array}{l}\text { Tests for deviation from } \\
\text { Hardy-Weinberg equilibrium }\end{array}$} & \multicolumn{5}{|c|}{ Tests for association $(95 \% \mathrm{Cl})$} \\
\hline & Controls & PCOS & $\begin{array}{l}\text { Allele freq. } \\
\text { Difference }\end{array}$ & Heterozygous & Homozygous & Allele Positivity & $\begin{array}{c}\text { Armitage's } \\
\text { trend test }\end{array}$ \\
\hline \multirow[b]{3}{*}{ 윤 } & $\mathrm{nTT}=38(37.56)$ & $\mathrm{nTT}=29(26.1)$ & \multicolumn{5}{|c|}{ Risk allele T } \\
\hline & $\begin{array}{l}\mathrm{nAT}=38(37.89) \\
\mathrm{nAA}=10(9.56)\end{array}$ & $\begin{array}{l}\mathrm{nAT}=41(45.8) \\
\mathrm{nAA}=21(20.1)\end{array}$ & {$[\mathrm{T}]<->[A]$} & {$[\mathrm{TT}]<->[\mathrm{AT}]$} & {$[\mathrm{TT}]<->[\mathrm{AA}]$} & {$[\mathrm{TT}]<->[\mathrm{AT}+\mathrm{AA}]$} & Common OR \\
\hline & $\begin{array}{c}f_{\_} \mathrm{a} 1=0.66 \pm 0.037 \\
F=0.0234 \\
p=0.829 \text { (Pearson) } \\
p=0.829 \text { (Llr) } \\
p=0.81 \text { (Exact) }\end{array}$ & $\begin{array}{c}f_{-a}=0.53 \pm 0.039 \\
F=0.1267 \\
p=0.224 \text { (Pearson) } \\
p=0.224 \text { (Llr) } \\
p=0.216 \text { (Exact) }\end{array}$ & $\begin{array}{c}\text { Odds_ratio }=1.74 \\
\text { C.I. }=[1.131-2.675] \\
\text { chi2 }=6.4 \\
\mathbf{p}=\mathbf{0 . 0 1 1 4}(\mathbf{P})\end{array}$ & $\begin{array}{c}\text { Odds_ratio }=1.417 \\
\text { C.I. }=[0.733-2.736] \\
\text { chi2 } 2=1.08 \\
p=0.299\end{array}$ & $\begin{array}{c}\text { Odds } \\
\text { ratio }=3.014 \\
\text { C.I. }=[1.243-7.309] \\
\text { chi2 }=6.18 \\
\mathbf{p}=\mathbf{0 . 0 1 2 9}\end{array}$ & $\begin{array}{c}\text { Odds } \\
\text { ratio }=1.756 \\
\text { C.I. }=[0.95-3.244] \\
\text { chi2 }=3.26 \\
p=0.071\end{array}$ & $\begin{array}{c}\text { Odds } \\
\text { ratio }=1.705 \\
\text { chi2 }=5.84 \\
\mathbf{p}=\mathbf{0 . 0 1 5 7}\end{array}$ \\
\hline
\end{tabular}

$\mathrm{OR}$ - odds ratio; $\mathrm{Cl}$ - confidence interval

\begin{tabular}{|c|c|c|c|c|c|c|c|c|c|}
\hline & \multicolumn{4}{|c|}{ Control Group $(n=86)$} & \multicolumn{4}{|c|}{ PCOS patients $(n=91)$} & \multirow[b]{2}{*}{$\mathbf{p}$} \\
\hline & $A A(n=10)$ & AT $(n=38)$ & $\operatorname{TT}(n=38)$ & Total & $A A(n=21)$ & AT $(n=41)$ & $\operatorname{TT}(n=29)$ & Total & \\
\hline Spexin [ng/mL] & $11.27 \pm 8.01$ & $10.62 \pm 6.49$ & $14.794 \pm 12.35$ & $12.61 \pm 9.76$ & $11.92 \pm 8.29$ & $9.65 \pm 8.36$ & $10.89 \pm 10.91$ & $10.54 \pm 9.20$ & 0.143 \\
\hline Adionectin [ng/mL] & $12.25 \pm 7.13$ & $12.83 \pm 8.33$ & $15.09 \pm 9.55$ & $10.15 \pm 6.15$ & $11.122 \pm 7.33$ & $9.85 \pm 5.74$ & $10.22 \pm 6.18$ & $13.88 \pm 8.76$ & 0.471 \\
\hline Leptin [pg/mL] & $1591.1 \pm 639.5$ & $1698.0 \pm 877.8$ & $1697.9 \pm 724.8$ & $1670.8 \pm 786.1$ & $1913.6 \pm 1062.3$ & $1820.0 \pm 897.3$ & $1867.3 \pm 823.5$ & $1874.2 \pm 902.3$ & 0.21 \\
\hline BMI $\left[\mathrm{kg} / \mathrm{m}^{2}\right]$ & $23.99 \pm 5.18$ & $24.69 \pm 4.10$ & $23.61 \pm 4.63$ & $24.09 \pm 4.43$ & $26.55 \pm 6.69$ & $25.71 \pm 4.95$ & $25.84 \pm 4.44$ & $26.01 \pm 5.25$ & 0.80 \\
\hline HOMA-IR & $1.71 \pm 1.84$ & $1.84 \pm 1.11$ & $2.11 \pm 1.50$ & $1.93 \pm 1.38$ & $3.25 \pm 2.63$ & $2.84 \pm 2.23$ & $2.57 \pm 1.17$ & $2.88 \pm 2.06$ & 0.62 \\
\hline
\end{tabular}

$\mathrm{BMI}$ - body mass index; PCOS - polycystic ovarian syndrome

Genotype distribution in the control group was as follows: out of 86 cases, 38 had the wild (TT) genotype, 38 had the heterozygous genotype (AT), and 10 had the mutant genotype (AA). The frequency of the A-allele carriers on rs9939609 was significantly increased in PCOS cases compared with healthy controls $(46,6 \%$ vs $33,5 \%$ respectively, $\mathrm{p}=0.01)$. The present data indicates that the conversion of a T allele to A in PCOS cases (allele frequency differences) increased PCOS risk 1.74 times when compared the general healthy women population $[\mathrm{OR}=1.74 ; \mathrm{Cl}=(1.131-2.675)$; $\left.X^{2}=6.40, p=0.0114\right]$ (Tab. 3). When homozygous genotypes compared each other's PCOS patients with AA genotype increase the risk approximately three times more than wild type genotype [TT vs AA genotype, $\mathrm{OR}=3.014, \mathrm{Cl}=(1.24-$ $-7.31) ; x^{2}=6.18, p=0.013$ ]. Furthermore, rs9939609 was found significantly associated with PCOS under a recessive model $[\mathrm{OR}=2.5 ; \mathrm{Cl}=(1.11-5.62) ; \mathrm{p}=0.027]$.

No significant difference was observed in PCOS women in respect to serum spexin, adiponectin and leptin levels in carriers of the genotypes of FTO+ rs9939609 polymorphism ( $p>0.05$ for all). In the healthy controls, serum spexin, adiponectin and leptin levels in carriers of genotypes TT, AT, and AA of FTO rs9939609 polymorphism were also not significantly different (Tab. 4).

\section{DISCUSSION}

PCOS is associated with gradual weight gain, obesity and development of metabolic syndrome with dyslipidemia and IR. In this context, adipocytokine dysregulation and genetic aberrations are common features of PCOS and these alterations are usually secondary to obesity, hyperandrogenism, and/or hyperinsulinemia. Our findings in the present study strongly support these observations indicating that serum adiponectin and leptin levels are affected in PCOS patients depending on the BMI status. Serum spexin levels did not differ between study groups. No significant correlation observed between serum spexin levels and other two adipocytokines except for adiponectin in PCOS patients with $\mathrm{BMI}<25 \mathrm{~kg} / \mathrm{m}^{2}$.

Our finding that spexin concentration did not vary significantly between obese and lean PCOS patients vs healthy controls is of great value because there is no study in literature depicting the role of spexin in PCOS patients. Moreover, we could not identify any relation between circulating spexin and other metabolic or hormonal characteristics, including body composition or IR. Spexin is a novel peptide hormone that was first identified by Mirabeau et al. [16], by using an approach based on hidden Markov model. It has been shown to be involved in weight regulation with poten- 
tial for obesity treatment and has been demonstrated to be expressed in a variety of body organs and tissues $[17,19,20]$. The finding of spexin levels that were not affected from BMI levels of study participants is not an expected result according to the literature. It is expected that the spexin level must be higher in obese cases because it is produced in fatty tissue. So, it can be proposed that similar spexin levels in PCOS cases irrespective from BMI status have a different etiologic mechanism. In a recent study by Chen et al. [21], it has been demonstrated that serum spexin levels are decreased in obese subjects and was negatively correlated with insulin resistance. Similarly, Al-Daghri and colleagues [17] demonstrated that low serum levels of spexin are slightly related with components of metabolic syndrome.

In this study, we also demonstrated that PCOS women have low levels of adiponectin and this finding is dependent on BMI. Therefore, the outcomes of the present study support the current knowledge indicating that a link exists between PCOS and decreased serum adiponectin levels. Apart from being an exclusive product of adipocyte cells, adiponectin plays a significant role in different physiological and pathological processes including inflammation, metabolic syndrome and atherosclerosis [22, 23]. Thus, obesity is an essential characteristic of PCOS, which can decrease the quantity of adiponectin by modifications in the expression of adiponectin receptors and diminishes the adiponectin sensitivity. Therefore, decreased serum levels of adiponectin among the overweight patients with PCOS were mainly ascribed to the coexistence or interaction between PCOS and obesity [23]. Contrary to these findings Panidis et al. [24], demonstrated that adiponectin levels were only lower in overweight/obese patients with PCOS compared to healthy non-obese PCOS patients. Therefore, authors suggested that adiponectin might not have a significant role in PCOS pathogenesis.

We found significantly increased serum leptin levels in PCOS women compared to healthy controls. There are different studies in literature reaching varied conclusions where both high concentrations and unchanged levels of leptin in PCOS patients have been determined [23, 25-27]. Daghestani et al. [27], reported no significant difference between PCOS and controls in terms of leptin levels. But similar to our findings, Mitkov et al [28], Pekhlivanov et al. [29], and Yang et al. [30], reported increased leptin levels in PCOS patients. Therefore, it can be suggested that with having a dual effect on reproduction, elevated serum leptin levels may have a pathophysiological role in PCOS development [27].

As mentioned above, the association between PCOS and different kind of adipocytokines has been well documented in literature, but the relation between FTO+ rs9939609 variant and these variables has not been well studied. In this context, this study also explored wheth- er FTO gene polymorphism influences PCOS development or if there is a possible association between circulating adipocytokines and FTO rs9939609 variant. We found that the variant allele of FTO rs9939609 was related with PCOS development. Our finding is in line with the research findings of Li et al. [31], in which the authors designed a two-phase trial consisting 3599 PCOS women and 3082 healthy controls. As a result, they have demonstrated that FTO rs9939609 variant is associated with Chinese PCOS women irrespective from the existence of obesity. A recent meta-analysis by Liu et al. [32], also confirmed these findings and demonstrated that rs9939609 A/T polymorphism of FTO gene is related with increased risk of PCOS development, and that A allele is a risk factor for PCOS susceptibility simultaneously. Although, the function, the involved biological pathways and the mechanism by which the FTO rs9939609 variant affects body size and predicts the risk of PCOS is still indefinite, this association is more likely to be explained by increased adiposity. Unfortunately, we are unable to demonstrate the association between FTO rs9939609 variant with BMI and circulating adipocytokines, which could be due to inadequate power of the study.

It is crucial to recognize some limitations associated with the present study that could potentially offer a platform for future studies. First, the serum adipocytokine levels may not reflect all events associated to adipocytokines. It would have been noteworthy to measure inflammation markers simultaneously given that PCOS and obesity are associated to long-standing low-grade inflammation. Second, due to relatively small size of study population large-scale studies are required to confirm the association between FTO SNPS and PCOS susceptibility.

\section{CONCLUSIONS}

In conclusion, we demonstrated lower levels of adiponectin, increased levels of leptin and unaltered spexin levels in PCOS patients. Moreover, we reported that single nucleotide polymorphisms (SNPs) in the FTO gene modify PCOS risk and does not appear to be influenced by IR status or obesity.

\section{Conflict of interest}

No conflict of interest was declared by the authors.

\section{Funding}

This research is supported by The Scientific Research Projects Coordination Unit of Canakkale Onsekiz Mart University (Project ID: TSA-2018-1378).

\section{Financial disclosure}

No financial disclosure was declared by the authors. 


\section{REFERENCES}

1. Delitala AP, Capobianco G, Delitala G, et al. Polycystic ovary syndrome, adipose tissue and metabolic syndrome. Arch Gynecol Obstet. 2017; 296(3): 405-419, doi: 10.1007/s00404-017-4429-2, indexed in Pubmed: 28643028.

2. Nandi A, Chen Z, Patel R, et al. Polycystic ovary syndrome. Endocrinol Metab Clin North Am. 2014;43(1): 123-147, doi: 10.1016/j.ecl.2013.10.003, indexed in Pubmed: 24582095.

3. Olszanecka-Glinianowicz M, Kuglin D, Dąbkowska-Huć A, et al. Serum adiponectin and resistin in relation to insulin resistance and markers of hyperandrogenism in lean and obese women with polycystic ovary syndrome. Eur J Obstet Gynecol Reprod Biol. 2011; 154(1): 51-56, doi: 10.1016/j.ejogrb.2010.08.022, indexed in Pubmed: 20889251.

4. Nambiar V, Vijesh VV, Lakshmanan P, et al. Association of adiponectin and resistin gene polymorphisms in South Indian women with polycystic ovary syndrome. Eur J Obstet Gynecol Reprod Biol. 2016; 200: 82-88, doi: 10.1016/j.ejogrb.2016.02.031, indexed in Pubmed: 26995146.

5. Mobeen H, Afzal N, Kashif M. Polycystic Ovary Syndrome May Be an Autoimmune Disorder. Scientifica (Cairo). 2016; 2016: 4071735, doi: 10.1155/2016/4071735, indexed in Pubmed: 27274883.

6. Zhao H, Lv Y, Li L, et al. Genetic Studies on Polycystic Ovary Syndrome. Best Pract Res Clin Obstet Gynaecol. 2016; 37: 56-65, doi: 10.1016/j. bpobgyn.2016.04.002, indexed in Pubmed: 27264388.

7. Liu AiL, Xie HJ, Xie HY, et al. Association between fat mass and obesity associated (FTO) gene rs9939609 A/T polymorphism and polycystic ovary syndrome: a systematic review and meta-analysis. BMC Med Genet. 2017; 18(1): 89, doi: 10.1186/s12881-017-0452-1, indexed in Pubmed: 28826396.

8. Demirci H, Yilmaz M, Ergun MA, et al. Frequency of adiponectin gene polymorphisms in polycystic ovary syndrome and the association with serum adiponectin, androgen levels, insulin resistance and clinical parameters. Gynecol Endocrinol. 2010; 26(5): 348-355, doi: 10.3109/09513590903367051, indexed in Pubmed: 20388053.

9. Hubacek JA, StanekV, Gebauerová M, et al. A FTO variant and risk of acute coronary syndrome. Clin Chim Acta. 2010; 411(15-16): 1069-1072, doi: 10.1016/j.cca.2010.03.037, indexed in Pubmed: 20362563.

10. Barber TM, Bennett AJ, Groves CJ, et al. Association of variants in the fat mass and obesity associated (FTO) gene with polycystic ovary syndrome. Diabetologia. 2008; 51(7): 1153-1158, doi: 10.1007/s00125-008-1028-6, indexed in Pubmed: 18478198.

11. Yan Q, Hong J, Gu W, et al. Association of the common rs9939609 variant of FTO gene with polycystic ovary syndrome in Chinese women. Endocrine. 2009; 36(3): 377-382, doi: 10.1007/s12020-009-9257-0, indexed in Pubmed: 19859840.

12. Carmina E, Orio F, Palomba S, et al. Evidence for altered adipocyte function in polycystic ovary syndrome. Eur J Endocrinol. 2005; 152(3): 389-394, doi: 10.1530/eje.1.01868, indexed in Pubmed: 15757855.

13. Pangaribuan $B$, Yusuf $I$, Mansyur $M$, et al. Serum adiponectin and resistin in relation to insulin resistance and markers of hyperandrogenism in lean and obese women with polycystic ovary syndrome. Ther Adv Endocrinol Metab. 2011; 2(6): 235-245, doi: 10.1177/2042018811423770, indexed in Pubmed: 23148188.

14. Unger RH. Leptin physiology: a second look. Regul Pept. 2000; 92(13): 87-95, doi: 10.1016/s0167-0115(00)00154-3, indexed in Pubmed: 11024570.

15. Rolland YM, Haren MT, Patrick $P$, et al. Adiponectin levels in obese and non-obese middle-aged African-American women. Obes Res Clin Pract. 2007; 1(1): 1-78, doi: 10.1016/j.orcp.2006.10.002, indexed in Pubmed: 24351429.

16. Mirabeau $O$, Perlas $E$, Severini $C$, et al. Identification of novel peptide hormones in the human proteome by hidden Markov model screening.
Genome Res. 2007; 17(3): 320-327, doi: 10.1101/gr.5755407, indexed in Pubmed: 17284679 .

17. Al-Daghri NM, Alenad A, Al-Hazmi $\mathrm{H}$, et al. Spexin Levels Are Associated with Metabolic Syndrome Components. Dis Markers. 2018; 2018: 1679690, doi: 10.1155/2018/1679690, indexed in Pubmed: 30254709.

18. Matthews DR, Hosker JP, Rudenski AS, et al. Homeostasis model assessment: insulin resistance and beta-cell function from fasting plasma glucose and insulin concentrations in man. Diabetologia. 1985; 28(7): 412-419, doi: 10.1007/BF00280883, indexed in Pubmed: 3899825.

19. Gu L, MaY, Gu M, et al. Spexin peptide is expressed in human endocrine and epithelial tissues and reduced after glucose load in type 2 diabetes. Peptides. 2015; 71: 232-239, doi: 10.1016/j.peptides.2015.07.018, indexed in Pubmed: 26211893.

20. Ma A, He M, Bai J, et al. Dual Role of Insulin in Spexin Regulation: Functional Link Between Food Intake and Spexin Expression in a Fish Model. Endocrinology. 2017; 158(3): 560-577, doi: 10.1210/en.2016-1534, indexed in Pubmed: 28359089.

21. Chen T, Wang F, Chu Z, et al. Circulating Spexin Decreased and Negatively Correlated with Systemic Insulin Sensitivity and Pancreatic $\beta$ Cell Function in Obese Children. Ann Nutr Metab. 2019; 74(2): 125-131, doi: 10.1159/000496459, indexed in Pubmed: 30673665.

22. Tsao TS, Lodish HF, Fruebis J. ACRP30, a new hormone controlling fat and glucose metabolism. Eur J Pharmacol. 2002; 440(2-3): 213-221, doi: 10.1016/s0014-2999(02)01430-9, indexed in Pubmed: 12007537.

23. Behboudi-Gandevani S, Ramezani Tehrani F, Bidhendi Yarandi R, et al.The association between polycystic ovary syndrome, obesity, and the serum concentration of adipokines. J Endocrinol Invest. 2017; 40(8): 859-866, doi: 10.1007/s40618-017-0650-x, indexed in Pubmed: 28332170.

24. Panidis D, Kourtis A, Kukuvitis $A$, et al. Serum adiponectin levels in women with polycystic ovary syndrome. Hum Reprod. 2003; 18(9): 17901796, doi: 10.1093/humrep/deg353, indexed in Pubmed: 12923129.

25. Sarray S, Madan S, Saleh LR, et al. Validity of adiponectin-to-leptin and adiponectin-to-resistin ratios as predictors of polycystic ovary syndrome. Fertil Steril. 2015; 104(2): 460-466, doi: 10.1016/j.fertnstert.2015.05.007, indexed in Pubmed: 26051098.

26. Rotterdam ESHRE/ASRM-Sponsored PCOS Consensus Workshop Group. Revised 2003 consensus on diagnostic criteria and long-term health risks related to polycystic ovary syndrome. Fertil Steril. 2004; 81(1): 19-25.

27. Daghestani $M H$, Daghestani $M$, Daghistani $M$, et al. A study of ghrelin and leptin levels and their relationship to metabolic profiles in obese and lean Saudi women with polycystic ovary syndrome (PCOS). Lipids Health Dis. 2018; 17(1): 195, doi: 10.1186/s12944-018-0839-9, indexed in Pubmed: 30131073

28. Mitkov M, Pehlivanov B, Orbetzova M. Serum ghrelin level in women with polycystic ovary syndrome and its relationship with endocrine and metabolic parameters. Gynecol Endocrinol. 2008; 24(11): 625-630, doi: 10.1080/09513590802302233, indexed in Pubmed: 19031219.

29. Pekhlivanov B, Mitkov $M$, Orbtsova $M$, et al. [Serum levels of ghrelin and leptin in women with polycystic ovary syndrome]. Akush Ginekol (Sofiia). 2008; 47(3): 15-19, indexed in Pubmed: 18756827.

30. Yang R, Barouch LA. Leptin signaling and obesity: cardiovascular consequences. Circ Res. 2007; 101(6): 545-559, doi: 10.1161/CIRCRESAHA.107.156596, indexed in Pubmed: 17872473.

31. Li T, Wu K, You Li, et al. Common variant rs9939609 in gene FTO confers risk to polycystic ovary syndrome. PLoS One. 2013; 8(7): e66250, doi: 10.1371/journal.pone.0066250, indexed in Pubmed: 23840863.

32. Liu AiL, Xie HJ, Xie HY, et al. Association between fat mass and obesity associated (FTO) gene rs9939609 A/T polymorphism and polycystic ovary syndrome: a systematic review and meta-analysis. BMC Med Genet. 2017; 18(1): 89, doi: 10.1186/s12881-017-0452-1, indexed in Pubmed: 28826396. 